\title{
Subindo ao Chiado
}

\section{Ana Campos}

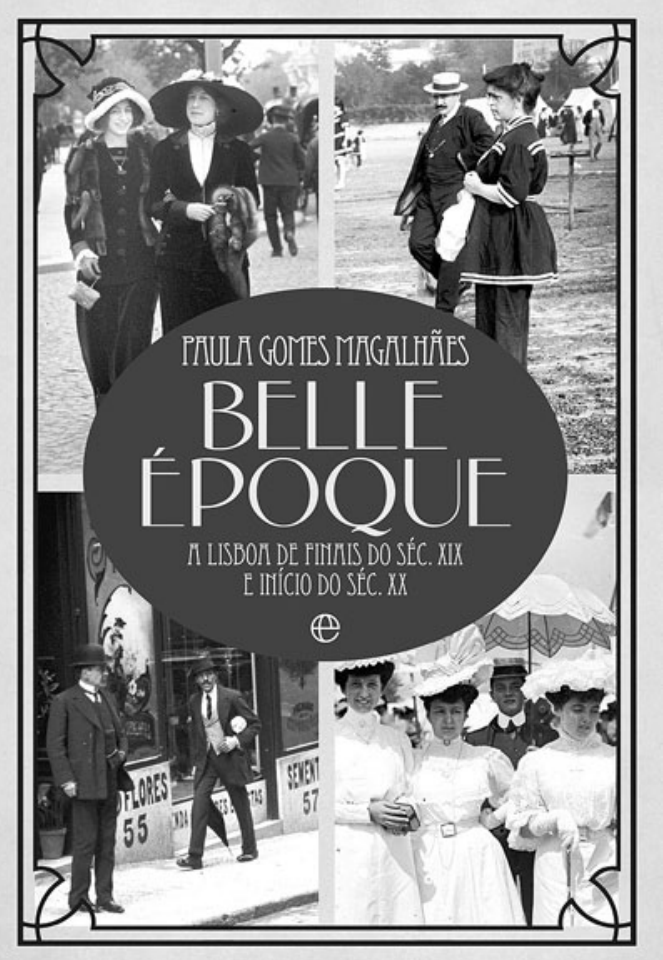

Paula Gomes Magalhães, Belle Époque: $A$ Lisboa de finais do séc. XIX e início do séc. XX.,Lisboa, A Esfera dos Livros, 2014, 376 pp.

Como quem passeia pelas ruas de Lisboa, neste seu livro Paula Gomes de Magalhães descreve a ebulição da que terá sido a vida na capital durante a Belle Époque, que se iniciaria em 1880, havendo porém discordâncias a este respeito, para terminar na data mais consensual de 1914, coincidindo com o eclodir da I Grande Guerra.

Este passeio, para que a autora nos convida, é feito em quatro etapas, tantos são os capítulos da obra.

Em "Lisboa a traços largos no tempo da Belle Époque», é-nos dado um enquadramento social e político daqueles anos de grande turbulência. Portugal assistiu estupefacto ao Ultimatum inglês e às mobilizações republicanas sob uma agonizante monarquia, que acabariam por culminar no regicídio de 1908 e, dois anos depois, na implantação da República. Portugal entretanto deslumbrava-se com os costumes que ia importando quer de Inglaterra, como as garden-parties, quer de Paris, paraíso ainda então dos boémios, artistas e afortunados viajantes. Abriram nesta época grandes armazéns como os do Chiado, Grandella e Ramiro Leão, que traziam até às melhores casas da capital vestuário, acessórios, tecidos, adereços e todo o tipo de luxos que se podiam importar das mecas da moda, pelos quais suspiravam as burguesinhas e aristocratas quando folheavam as revistas da especialidade. Ao mesmo tempo, rasgavam-se Avenidas como a da Liberdade e Fontes Pereira de Melo, requalificavam-se bairros populares e sonhava-se com uma cidade progressista que pudesse acompanhar as mais avançadas cidades da Europa, se não mesmo do Mundo, tal como ansiado pelos devaneios dos futuristas. Recordem-se, por exemplo, os sonhos do Engenheiro Melo de Matos que, no seu conto "Lisboa do ano 2000", publicado na Ilustração Portuguesa em 1906, prevê um metropolitano aéreo sobrevoando a cidade que já seria, então, o porto de recepção de toda a marinha mundial.

Mas nem tudo eram rosas. Em "Uma cidade de contrastes» a autora presta especial atenção ao modo como conviviam em Lisboa os mais avançados resultados da tecnologia, como o automóvel, com os costumes tradicionais, como o burro, utilizado pelos demais. No rigor da sua análise, Paula Gomes Magalhães reflecte ainda sobre as desigualdades sociais gritantes entre as classes mais abastadas e as mais desfavorecidas que viviam, na maior parte dos casos, "no meio da rua (uma vez que as casas não tinham o mínimo de conforto), nela catando piolhos, bisbilhotando sobre a vida alheia, assando sardinhas, cantando o fado ou levando de porta em porta quase tudo o que havia para vender" (p.137).

E da rua passamos para o interior das casas, para aposentos, alcovas e enxergas em "Lisboa íntima», capitulo em que se examina a vida privada dos casais e a dos que não beneficiavam de companhia legítima. Entramos no quarto dos nossos antepassados para perceber o quanto evoluímos na vivência da nossa sexualidade, ainda que esta nem sempre fosse tão recatada como desejavam aqueles que se dispunham a dar conselhos nestas áreas. Veja-se, por exemplo, A noite de núpcias: Estudos sobre a virgindade (1903) de Luis Salazar, citado pela autora. Os celibatários, por vocação ou por partida do destino, não são esquecidos por Paula Gomes Magalhães, que nos convida também a observar não só o intemporal mundo 
22 de Abril de 1912,
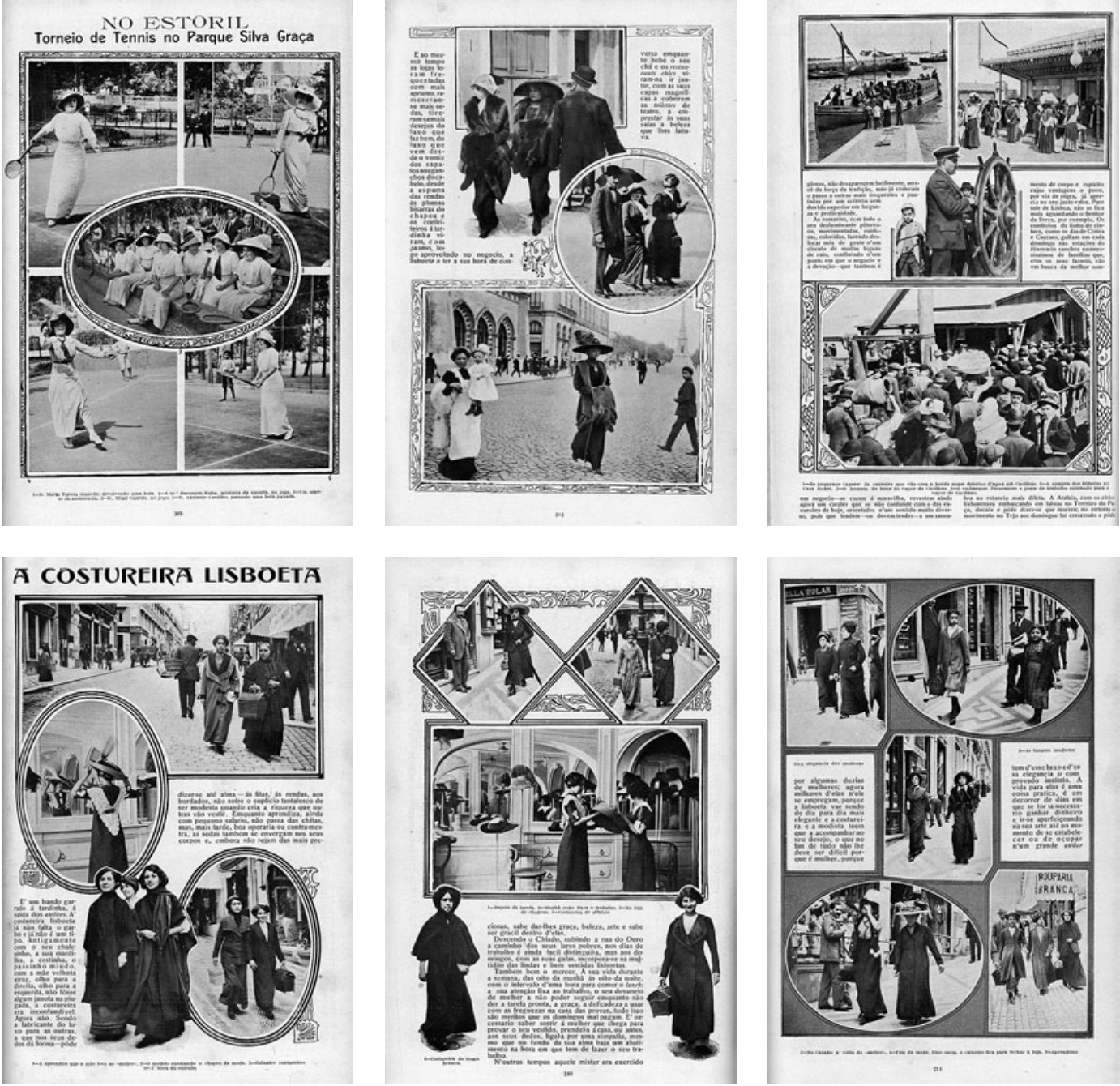

da prostituição, mas, ainda mais interessante, o modo como, num período em que as mulheres dependiam de um casamento para sobreviver, pelo menos nas classes em que Ihes não era permitido trabalhar, eram encontrados expedientes para contornar a situação das menos bafejadas por Cupido. Emblemáticos, os curiosos anúncios publicados em periódicos da época, como aquele em que uma senhora "oriunda da província, com casa mas sem família, solicitava uma pessoa de respeito que a protegesse." (p.174).

No último capítulo, "A Lisboa que se diverte», são passadas em revista as recreações, desportos e outras ocupações de tempos livres de todas as classes e grupos sociais, desde os mais antigos (como a já então muito decadente vida boémia) às novidades (como o animatógrafo, que competirá pelas décadas seguintes com o teatro).

Detenhamo-nos então nesta arte entusiasticamente lembrada pela autora no subcapítulo "Todos ao teatro!», para onde afluía todo o tipo de público, distribuindo-se pelo Avenida, Trindade, Ginásio, Nacional, São Carlos, e por muitos outros, de acordo com a bolsa, onde se representavam géneros diversos, desde revistas a vaudeville teatro declamado, operetas e imponentes óperas. A ida ao teatro era não só uma oportunidade de assistir a espectáculos nacionais ou estrangeiros em digressão pelo pais (muito populares entre o público ávido por novidades da Europa e das Américas), mas também um momento privilegiado de convívio social. Passeavam-se toilettes, esquadrinhavam-se os outros, viviam-se verdadeiros romances, uns legítimos outros nem tanto, cultivando-se mundanidades a tal ponto que as luzes da plateia não eram apagadas durante a representação, muitas vezes prestando-se pouca ou nenhuma atenção à cena. Actores como Taborda, fiel ao Ginásio, granjeavam público certo, e a vinda de vedetas internacionais como Sarah Bernhardt repercutia-se nos sucessos de bilheteira, tornando-se pretexto para artigos em números e números de revistas da especialidade, de modas e coscuvilhices.

Belle Époque consegue transmitir o fervilhar da capita no fim de século e a paixão da autora pelo período em questão. Obra profusamente documentada, como podemos confirmar pela bibliografia e as fontes generosamente partilhadas com os leitores na secção final, baseou-se na atenta análise de periódicos e outros abundantes materiais, de e sobre esse momento nas mais variadas áreas. Pecará apenas, talvez, por um excesso de citações que ilustram com perfeição o percurso e à-vontade da autora, mas que nos fazem sentir falta de mais prosa original tão entusiasmada. Muito interessantes e dignas de nota são também as muitas reproduções fotográficas que complementam o texto, tornando o livro um atraente bilhete-postal deste periodo quase mítico mas pouco conhecido, bem como uma importante antologia documental. 